\title{
PREPARATION AND CHARACTERIZATION OF A QUERCETIN-TETRAETHYL ETHER-BASED PHOTOPROTECTIVE NANOEMULSION
}

\author{
Marlucy da Cruz Gonçalves a, Viviane Martins R. dos Santos ${ }^{\mathrm{a}, *, \mathbb{B}}$, Jason Guy Taylora ${ }^{\mathrm{a}}$, Fernanda Barçante Perasoli ${ }^{\mathrm{b}}$, Orlando \\ David H. dos Santos ${ }^{\mathrm{b}}$, Ana Carolina S. Rabelo ${ }^{\mathrm{c}}$, Joamyr Victor Rossoni Junior ${ }^{\mathrm{c}}$, Daniela Caldeira Costa ${ }^{\mathrm{c}}$ and Thiago Cazati ${ }^{\mathrm{d}}$ \\ aDepartamento de Química, Instituto de Ciências Exatas e Biológicas, Universidade Federal de Ouro Preto, Campus Morro do \\ Cruzeiro, 35400-000 Ouro Preto - MG, Brasil \\ bDepartamento de Farmácia, Escola de Farmácia, Universidade Federal de Ouro Preto, Campus Morro do Cruzeiro, 35400-000 \\ Ouro Preto - MG, Brasil \\ 'Departamento de Ciências Biológicas, Instituto de Ciências Exatas e Biológicas, Universidade Federal de Ouro Preto, Campus \\ Morro do Cruzeiro, 35400-000 Ouro Preto - MG, Brasil \\ dDepartamento de Física, Instituto de Ciências Exatas e Biológicas, Universidade Federal de Ouro Preto, Campus Morro do \\ Cruzeiro, 35400-000 Ouro Preto - MG, Brasil
}

Recebido em 17/09/2018; aceito em 24/01/2019; publicado na web em 13/03/2019

\begin{abstract}
Although Quercetin absorbs in the UVA/UVB electromagnetic region, it is limited for applications as a UV filter due to its low lipophilicity and capacity to penetrate the epidermis. In order to overcome this limitation, we synthetized and evaluated the photo protective properties of a derivative obtained from Quercetin. The derivative was prepared by alkylation of Quercetin with iodoethane and characterized by IR and NMR spectroscopy. The in vitro Solar Protection Factor was determined by the Mansur method and the cytotoxicity was evaluated using hepatocellular cell (Hep G2) cells. Finally, Quercetin and the corresponding derivative were incorporated in nanoemulsions. Nanoemulsions with particles sizes between 53 and $73 \mathrm{~nm}$ were obtained, and polydispersity indexes were around 0.1 , indicating good homogeneity of the nanoemulsion particles. The cell viability study for the Quercetin derivative indicated a very low cytotoxicity profile. The chemical modification of Quercetin resulted in a promising compound with improved properties desirable for skin penetration and incorporation into sunscreen formulations.
\end{abstract}

Keywords: sun protection factor; sunscreen; photo protection; organic synthesis; quercetin.

\section{INTRODUCTION}

The ultraviolet (UV) radiation that reaches the earth's surface is one the main factors responsible for causing skin cancers in many people, and its frequency has increased in recent years. ${ }^{1} \mathrm{UV}$ rays burn the skin, induce premature aging and skin cancer. For this reason, the use of sunscreens and sunblocks is a common method for providing sunprotection to the skin. ${ }^{1}$ The growth in commercially available products containing sunscreens indicates that, even if a tan is still desired, people are conscious of the possible danger of photo-aging and skin cancer, occurring as a result of overexposure to the sun. ${ }^{2}$ The search for sun protection has intensified in recent decades as the sun's harmful effects have become more known and publicized. ${ }^{3}$ Recent studies aimed towards the development of new compounds with photoprotective applications have included otocrylene analogues, ${ }^{4}$ bis(indolyl)methane derivatives, ${ }^{5}$ vaniline derivatives, ${ }^{6}$ bile acids/azastilbenes conjugates, ${ }^{7}$ $N$-acyl hydrazone compounds ${ }^{8}$ and benzophenone derivatives. ${ }^{9}$ The photoprotective action of a sunscreen is measured universally by the sun protection factor (SPF) which establishes a correlation between the dose of sun exposure with the concentration of photoprotective product applied without the occurrence of erythema. Thus, the higher the SPF the greater the time allowed for safe exposure. The SPF is applied exclusively to UVB radiation, because it causes erythema. ${ }^{10}$ Topical sunscreens can have several pharmaceutical forms, like: oils, gels, emulsions, among others. ${ }^{11}$ Emulsions are the most suitable vehicle for the preparation of sunscreens, since they have a number of advantages, such as: the affinity for the epicutaneous mantle, the formation of thick film on the skin, ensuring a better fixation of the

*e-mail: vivianesantos@ufop.edu.br photoprotectors, increasing the resistance to water, compatibility with different ranges of $\mathrm{pH}$ and the possibility for incorporation of water soluble and liposoluble filters that act in synergy. ${ }^{12-15}$ The use of nanoemulsions in cosmetics becomes attractive because of the small size of the globules, which reduces the possibility of sedimentation, flocculation and coalescence, allowing the system to remain dispersed and without phase division, guaranteeing greater stability. ${ }^{16}$ Choquenet and co-workers have previously shown that Quercetin could potentially be used in sunscreen products and successfully incorporated this natural product in oil-in-water emulsions at a concentration of $10 \%$ (w/w). ${ }^{17}$ Moreover, Quercetin has exhibited photostabilizing properties that render it a useful additive for the formulation of effective broadspectrum sunscreens containing butyl methoxy dibenzoyl methane and octylmethoxycinnamate. ${ }^{18}$ A limitation however for the use of Quercetin as a UV filter is its low lipophilicity and capacity to penetrate the epidermis. Adequate percutaneous absorption is an essential requirement for topically applied photoprotective agents and Quercetin penetrates very poorly in to the stratum corneum. Given this limitation, we have synthesized a more lipophilic derivative of Quercetin by alkylation of quercetins free hydroxyl groups. ${ }^{19}$ Herein, we report the preparation of Quercetin 3,7,3',4'-tetraethyl ether and evaluation of is in vitro photoprotective activity, photostability, cellular viability and incorporation it an $\mathrm{O} / \mathrm{W}$ type nanoemulsion sunscreen formulation.

\section{EXPERIMENTAL}

\section{General considerations}

Reagents and solvents were purchased from Sigma Aldrich and used without further purification. The melting points were measured 
on the Büchi Melting Point B-540. NMR data were obtained with 200 $\mathrm{MHz}$ NMR instrument. Chemical shifts are reported in $\delta$ (ppm) with reference to residual protons and ${ }^{13} \mathrm{C}$ signals in deuterated solvent $\left(\mathrm{CDCl}_{3}\right)$ The UV-vis absorption measurements were performed with a Bel Engineering UV-M51 Spectrophotometer. The MTT (3-[4,5-dimethyl-thiazol-2-yl]-2,5-diphenyl tetrazolium bromide) cytotoxicity assay was performed using Hep G2 cells. A mechanical stirrer used for the production of the nanoemulsion was Fisatom ${ }^{\circledR}$ Mod.713. The granulometry of the nanoemulsion was determined by Photon Correlation Spectroscopy on the Malvern Zetasizer model ZS. For the development of nanoemulsions were used: a) Sunflower oil (Liza) - food oil; b) Croduret 50 - Special ${ }^{\circledR}$ (Croda) - hydrogenated and ethoxylated castor oil, surfactant with HLB of 14.1; designated by the CTFA as PEG-40 Hydrogenated Castor Oil; c) Crill 3 (Croda) - Sorbitan monostearate, surfactant with EHL of 4.7; named by CTFA Sorbitan stearate $\left(\mathrm{C}_{24} \mathrm{H}_{46} \mathrm{O}_{6}\right)$; d) Newly obtained distilled waterand e) Substance of interest (Quercetin and/or derivative and EthylhexylMethoxycinnamate).

\section{Synthesis of quercetin 3,7,3',4'-tetraethyl ether}

$0.755 \mathrm{~g}$ (2.49 mmol) of Quercetin, $7.5 \mathrm{~mL}$ of DMF, $1.552 \mathrm{~g}$ $(11.23 \mathrm{mmol})$ of potassium carbonate and $1 \mathrm{~mL}(12.50 \mathrm{mmol})$ of iodoethane were added to a $50 \mathrm{~mL}$ round bottomed flask. Stirring was allowed for two days at room temperature. The reaction solution was diluted with $30 \mathrm{~mL}$ of dichloromethane and $20 \mathrm{~mL}$ of $\mathrm{HCl}$ $\left(0.1 \mathrm{~mol} \mathrm{~L}^{-1}\right)$ and the resulting organic phase was separated and washed three times with $20 \mathrm{~mL}$ of water. Anhydrous sodium sulfate was added to dry the solution and the organic solvent was concentrated on rotary evaporator. Thin layer chromatography (TLC) of the crude product was carried out using 2:8 ethyl acetate/hexane as the eluent and the product presented an Rf equal to 0.72 compared which was greater than the Rf of the staring material Quercetin. Next, the product was purified by flash column chromatography employing silica gel and ethyl acetate/hexane 2:8. The product was obtained in $0.150 \mathrm{~g} \mathrm{(14 \%} \mathrm{yield)} \mathrm{as} \mathrm{a} \mathrm{yellow} \mathrm{solid} \mathrm{with} \mathrm{a} \mathrm{melting} \mathrm{point} \mathrm{in} \mathrm{the}$ range of $119-120^{\circ} \mathrm{C}\left(\text { lit }=116-120^{\circ} \mathrm{C}\right)^{20}$ and Octanol-Water partition coefficient (miLogP) of 4.61; IR (KBr) $v\left(\mathrm{~cm}^{-1}\right)$ : 2500-3500 (intense and wide band of $\mathrm{OH}$ associated), 3030 (C-H of aromatics), 1,600, $1,580,1,500$ and $1,450\left(\mathrm{C}=\mathrm{C}\right.$ of aromatics). $\mathrm{RMN}^{1} \mathrm{H}(200 \mathrm{MHz}$, DMSO-d6, ppm): 1.34 - $153(\mathrm{~m}, 12 \mathrm{H}) ; 4.14$ (q, $J=6.6,4 \mathrm{H}) ; 4.23$ $(\mathrm{q}, J=6.6,4 \mathrm{H}) ; 6,34(\mathrm{~s}, 1 \mathrm{H}) ; 6.43(\mathrm{~s}, 1 \mathrm{H}) ; 6.97(\mathrm{~d}, J=9.31 \mathrm{H}) ; 7.72$ $(\mathrm{d}, J=9.3,1 \mathrm{H})$ e $7.76(\mathrm{~s}, 1 \mathrm{H}) ;{ }^{13} \mathrm{CNMR}\left(50 \mathrm{MHz}, \mathrm{DMSO}-d_{6}, \mathrm{ppm}\right)$ : $14.8 ; 15.6 ; 64.1 ; 64.4 ; 64.8 ; 68.5 ; 92.5 ; 98.1 ; 109.5 ; 112.4 ; 113.8$; $122.1 ; 123.2 ; 137.9 ; 148.2 ; 151.2 ; 156.1 ; 156.7 ; 162.0 ; 164.7 ; 178.8$.

\section{In vitro determination of the Sun Protection Factor (SPF)}

The in vitro Solar Protection Factor (SPF) was determined by the spectrophotometric method developed by Mansur, ${ }^{20}$ using Eq. (1).

$$
\operatorname{SPF}=\mathrm{FC} \sum_{290}^{320} \operatorname{EE}(\lambda) \cdot \mathrm{I}(\lambda) \cdot \operatorname{Abs}(\lambda)
$$

where: $\mathrm{FC}=10$ (constant), $\mathrm{EE}=$ erythemogenic effect, $\mathrm{I}=$ Intensity of the sun and $\mathrm{Abs}=$ absorbance of the sample. Absorption readings were performed in the range of 290 to $320 \mathrm{~nm}$ with intervals of $5 \mathrm{~nm}$ and added in equation 1 .

The constants EE and I were pre-defined by Mansur, ${ }^{20}$ according to Table 1.

\section{Log P- octanol-water partition coefficient ${ }^{21}$}

The $\log \mathrm{P}$ octanol-water partition coefficient was calculated
Table 1. EE and I constants for the calculation of in vitro SPF

\begin{tabular}{cc}
\hline$\lambda(\mathrm{nm})$ & $\mathrm{EE}(\lambda) \mathrm{xI}(\lambda)$ \\
\hline 290 & 0.0150 \\
295 & 0.0817 \\
300 & 0.2874 \\
305 & 0.3278 \\
310 & 0.1864 \\
315 & 0.8390 \\
320 & 0.0180 \\
\hline$\sum$ & 1.0000
\end{tabular}

$\mathrm{EE}(\lambda)=$ erythemogenic effect of wavelength radiation, $\mathrm{I}(\lambda)=$ sun intensity at wavelength $(\lambda), \lambda=$ wavelength. ${ }^{20}$

using the online Molinspiration program Interactive log $\mathrm{P}$ calculator (software version v2015.01).

\section{Evaluation of photostability}

The photostability test was performed using a light chamber with a UVB lamp source. Solutions of $0.010 \mu \mathrm{g} \mathrm{mL} \mathrm{m}^{-1}$ Quercetin, derivative and a reference standard (Ethylhexylmethoxycinnamate) were prepared in methanol. The solutions were placed in volumetric flasks without a cap and exposed to radiation for total time of $2 \mathrm{~h}$ and evaluated at 20-minute intervals upon exposure to UV radiation. The system were open during the irradiation.

\section{Preparation of nanoemulsions}

The nanoemulsions were prepared according to the Emulsion Phase Inversion (EPI) method, ${ }^{22}$ However, to obtain the formulations, the distilled water and the oil phase were heated separately at $75 \pm 2{ }^{\circ} \mathrm{C}$. The water was slowly poured under the oil phase and the system was maintained under constant stirring at a speed of $520 \mathrm{rpm}$. Stirring was continued until the temperature was reached at $25 \pm 2{ }^{\circ} \mathrm{C}$. After $24 \mathrm{~h}$, all formulations were macroscopically evaluated. The compositions tested for nanoemulsions were the ones according to Table 2 .

\section{Determination of the granulometric distribution}

The formulations were analyzed for particle size distribution by Photon Correlation Spectroscopy (PCS). This technique is based on the incision of a laser beam on the sample to evaluate the light scattering resulting from the Brownian motion performed by the particles. The intensity of the scattered light forms a pattern of movement that allows to define the average diameter of these particles, whereas the smaller ones move faster, promoting greater modifications in this intensity. ${ }^{23,24}$ The samples were initially diluted at room temperature in ultrapure water (Milli-Q®) in a ratio of $1: 1000$, and then $3 \mathrm{~mL}$ were transferred to a quartz cuvette for analysis. The samples were subjected to light scattering at a fixed angle of $90^{\circ}$ at a temperature of $25^{\circ} \mathrm{C}$, and the measurements were taken in triplicates. ${ }^{25}$ The results were given as mean particle diameter \pm standard deviation (SD) and polydispersity index (PI) of nanoemulsions. The PI refers to the homogeneity of the particle size distribution present in the sample, and samples with PI values smaller than 0.3 are considered monodisperse, ie the particle size distribution in the sample is more homogeneous or narrow.

\section{Cell viability assay (MTT)}

Hepatocyte carcinoma (HepG2) cell line was acquired from the Cell Bank from the Federal University of Rio de Janeiro (UFRJ) and 
Table 2. Compositions tested to obtain nanoemulsions with Quercetin, derivative, standard Ethylhexylmethoxycinnamate, in addition to Quercetin and derivative

\begin{tabular}{|c|c|c|c|c|c|c|c|c|}
\hline \multicolumn{2}{|c|}{ Nanoemulsion with Quercetin } & \multicolumn{2}{|c|}{ Nanoemulsion with derivative } & \multicolumn{2}{|c|}{$\begin{array}{l}\text { Nanoemulsion with } \\
\text { Ethylhexylmethoxycinnamate }\end{array}$} & \multicolumn{2}{|c|}{$\begin{array}{c}\text { Nanoemulsion with } \\
\text { Quercetin and derivative }\end{array}$} & \multirow{2}{*}{$\frac{\mathrm{P}}{\mathrm{O}}$} \\
\hline Croduret 50 & $5 \%$ & Croduret 50 & $5 \%$ & Croduret 50 & $5 \%$ & Croduret 50 & $5 \%$ & \\
\hline Crill3 & $5 \%$ & Crill3 & $5 \%$ & Crill3 & $5 \%$ & Crill3 & $5 \%$ & $\mathrm{O}$ \\
\hline Sunflower oil & $5 \%$ & Sunflower oil & $5 \%$ & Sunflower oil & $5 \%$ & Sunflower oil & $5 \%$ & $\mathrm{O}$ \\
\hline Quercetin & $0.10 \%$ & Derivative & $0.10 \%$ & Neo-Heliopan ${ }^{\circledR}$ & $5 \%$ & $\begin{array}{l}\text { Quercetin and } \\
\text { derivative }\end{array}$ & $0.1 \% * *$ & $\mathrm{O}$ \\
\hline Distilled water & q.s.p & Distilled water & q.s.p & Distilled water & q.s.p & Distilled water & q.s.p & A \\
\hline
\end{tabular}

q.s.p = amount sufficient to complete $100 \mathrm{~mL}$. P=Phase: $\mathrm{O}=\mathrm{O}$ - ily, $\mathrm{A}=$ Aqueous. $* * 0.1 \%$ of each constituent (Quercetin and Quercetin 3,7,3',4'-tetraethyl ether).

was cultured in DMEM medium supplemented with 10\% FBS (fetal bovine serum), $1 \%$ glucose, $1 \%$ glutamine and $100 \mathrm{U} / \mathrm{mL}$ penicillin in a humidified atmosphere containing $5 \% \mathrm{CO}_{2}$ in air at $37^{\circ} \mathrm{C}$

Cell viability was determined using colorimetric MTT (3-[4,5-dimethyl-thiazol-2-yl]-2,5-diphenyl tetrazolium bromide) assay). In brief, HepG2 cells $\left(1 \times 10^{5}\right)$ were cultured in 96 well-plates with or without different concentrations of concentrations of Quercetin or derivatives of Quercetin (10, 50, 100, 200, 400, 500, 600 and $800 \mu \mathrm{mol} \mathrm{L}^{-1}$ ) for $24 \mathrm{~h}$. After incubation, medium was removed and $200 \mu \mathrm{L}$ of $5 \mathrm{mg} / \mathrm{mL}$ MTT solution was added and incubated at $37^{\circ} \mathrm{C}$ for further $2 \mathrm{~h}$.

The MTT solution was then removed and $100 \mu$ of DMSO were added to each well. The absorbance was read on ELISA reader at $570 \mathrm{~nm}$. For the assays, the calculation used to evaluate the percentage of cell viability was: Absorbance of treated cells / absorbance of control x 100 .

\section{RESULTS AND DISCUSSION}

\section{Synthesis of quercetin 3,7,3',4'-tetraethyl ether (derivative of quercetin)}

The reaction of the Quercetin with iodoethane occurred in the presence of inorganic base potassium carbonate and solvent dimethylformamide resulting in the formation of Quercetin derivative Quercetin 3,7,3',4'-tetraethyl ether. The phenolic hydroxyls present in Quercetin were alkylated according to Figure 1.

Quercetin 3,7,3',4'-tetraethyl ether is a known compound and comparison of its melting point and spectroscopic data (NMR and FTIR) with literature ${ }^{26,27}$ values confirmed the formation of product. The spectrum in the infrared region showed absorption bands characteristic of the product. The absorption band in $3400 \mathrm{~cm}^{-1}$ indicated the presence of a hydroxyl, which did not undergo alkylation reaction with iodoethane, due to intramolecular hydrogen bonding with the ketone group present in the structure. IR bands $\sim 3000 \mathrm{~cm}^{-1}$, 1650,1500 e $1450 \mathrm{~cm}^{-1}$, which are, respectively, the $\mathrm{CH}$ band of aromatics and $\mathrm{C}=\mathrm{C}$ of aromatics. The NMR spectra $\left({ }^{1} \mathrm{H}\right.$ and $\left.{ }^{13} \mathrm{C}\right)$ showed resonance signals corresponding to the ethoxy substituents $\left(\mathrm{OCH}_{2} \mathrm{CH}_{3}\right)$ formed by alkylation of the phenolic hydroxyls. The presence of a triplet integrating for eight hydrogens with chemical shift equal to $4.10 \mathrm{ppm}$ and a singlet in the ${ }^{13} \mathrm{C}$ spectrum with chemical shift of $64.4 \mathrm{ppm}$ was indicative of methylene group and a quartet integrating 12 hydrogens at $1.34 \mathrm{ppm}$ with its corresponding singlet in the ${ }^{13} \mathrm{C}$ spectrum at $14.8 \mathrm{ppm}$ confirmed the presence of methyl group.$^{28}$ In order to improve the liphophilicity of Quercetin, alkylation of the free hydroxyl groups with an iodoalkane was envisaged to improve the chemical properties so that the modified compound would more efficiently absorbed by the skin. The $\log \mathrm{P}$ of Quercetin $3,7,3$ ', 4'-tetraethyl ether is 4.61 and Quercetin is 1.68 . $\log \mathrm{P}>1$ the molecule has a lipophilic character and $\log \mathrm{P}<1$ the molecule has a hydrophilic character. The log P octanol-water partition coefficient was calculated using Molinspiration Interactive $\log \mathrm{P}$ calculator. ${ }^{29}$

\section{Solar Protection Factor}

The SPF was evaluated using the Mansur method..$^{20}$ The analysis was carried out on an ultraviolet spectrophotometer, where the values of the obtained absorbances were placed in equation 1 , and generated SPF values as presented in the Table 3. Ethylhexylmethoxy cinnamate (octinoxate) and 2-hydroxy-4-methoxylbenzophenone (oxybenzone) have been used as positive controls in previous studies. Octinoxate at a concentration of $0.010 \mathrm{mg} \mathrm{mL}^{-1}$ presented an SPF of 9.36 and the SPF of Oxybenzone at a concentration of $0.023 \mathrm{mg} \mathrm{mL}^{-1}$ was reported to be $6.90 .{ }^{27} \mathrm{By}$ analysis of the obtained data, we verified that the Quercetin and Quercetin 3, 7, 3', 4'-tetraethyl ether (QD) presented SPF proportional to the analyzed concentrations, that is, the higher non-toxic concentration (according to the cell viability test) the higher the Sun Protection Factor. Although chemical modification of Quercetin slightly lowered its SPF, the results are never the less promising and given the potential for improved skin absorption, the derivative compound would be more effective in acting as a UV filter.<smiles>CCOc1cc(O)c2c(=O)c(OCC)c(-c3ccc(OCC)c(OCC)c3)oc2c1</smiles> 
Table 3. SPF values calculated from Quercetin(Q) and Quercetin 3, 7, 3', 4'-tetraethyl ether (QD)

\begin{tabular}{ccccc}
\hline $\begin{array}{c}\text { Concentration } \\
(\mathrm{mg} / \mathrm{mL})\end{array}$ & $\begin{array}{c}\mathrm{SPF} \\
(\mathrm{Quercetin})\end{array}$ & $\begin{array}{c}\varepsilon_{\max } \\
\left(\mathrm{mmol} \mathrm{L}^{-1} \mathrm{~cm}^{-1}\right) \\
\lambda_{\max 300 \mathrm{~mm}}\end{array}$ & $\begin{array}{c}\text { SPF } \\
(\mathrm{QD})\end{array}$ & $\begin{array}{c}\varepsilon_{\max } \\
\left(\mathrm{mmol} \mathrm{L}^{-1} \mathrm{~cm}^{-1}\right) \\
\lambda_{\max =300 \mathrm{~nm}}\end{array}$ \\
\hline 0.010 & 5.46 & 19.24 & 4.95 & 22.32 \\
0.015 & 8.71 & 20.74 & 7.84 & 23.44 \\
0.020 & 12.28 & 21.32 & 10.82 & 24.12 \\
0.025 & 15.19 & 21.80 & 13.91 & 25.15 \\
0.030 & 18.36 & 22.45 & 16.21 & 24.57 \\
\hline
\end{tabular}

\section{Evaluation of photostability}

Quercetin, Quercetin 3,7,3',4'-tetraethyl ether and Ethyl-hexyl Methoxycinnamate were investigated separately in a photostability study in triplicate at room temperature. The temperature of the experiment was maintained constant throughout the total period of the experiment. The compounds were dissolved in methanol, forming solutions of concentration equal to $0.010 \mathrm{mg} \mathrm{mL}^{-1}$. The graphs depicted in Figure 2 show how the analyzed solutions behave, in terms of photostability, before and after exposure to UVB radiation. Quercetin showed minimal variation during the observed period of exposure to UV light. Quercetin 3,7,3',4'-tetraethyl ether showed a small decrease in absorbance after the first 20 minutes, but then stabilized over 40,60 and 80 minutes respectively. Similar results were observed for standard sunscreen agent Ethyl-hexyl Methoxycinnamate. The absorbance increase after $20 \mathrm{~min}$ in the Figure 2 a because occurred evaporation of the solvent and with that increased concentration.

\section{Nanoemulsions}

Physical appearance of nanoemulsions and determination of granulometry

The macroscopic analysis was performed and it was observed that the developed nanoemulsions presented transparent bluish aspects, characteristic of nanoemulsions. ${ }^{30}$ In addition, they were stable after $24 \mathrm{~h}$ of preparation. As can be seen in Table 4, the average particle diameters present in the formulations varied between $54.16 \pm 0.36 \mathrm{e}$ $75.27 \pm 0.04$. In all cases, the particle diameters are in the range that is characteristic for nanoemulsions. ${ }^{31,32} \mathrm{All}$ nanoemulsions presented PI values lower than 0.3 and thus are considered monodispersed. ${ }^{33}$

The size of the globules of an emulsion depends on the emulsification method employed. The results demonstrate the efficiency of the phase inversion emulsification method in obtaining nanoemulsions, since the presented deviations are small, characterizing a good homogeneity of the granulometric size of the nanoemulsions particles. In addition, the small particle size

Table 4. Granulometry and PI of the developed nanoemulsions formulation

\begin{tabular}{lcc}
\hline Formulations & $\begin{array}{c}\text { Average diameter } \\
(\mathrm{nm}) \pm \mathrm{SD}\end{array}$ & $\mathrm{PI} \pm \mathrm{DP}$ \\
\hline $\begin{array}{l}\text { Nanoemulsion Ethylhexyl Methoxycin- } \\
\text { namate }\end{array}$ & $75.27 \pm 0.04$ & $0.10 \pm 0.003$ \\
Nanoemulsion 0.1\% Quercetin & $53.95 \pm 0.06$ & $0.13 \pm 0.01$ \\
$\begin{array}{l}\text { Nanoemulsion 0.1\% Quercetin } \\
\text { 3,7,3',4'-tetraethyl ether }\end{array}$ & $54.16 \pm 0.36$ & $0.13 \pm 0.01$ \\
$\begin{array}{l}\text { Nanoemulsion 0.1\% Quercetin and 0.1\% } \\
\text { Quercetin 3,7,3',4'-tetraethyl ether }\end{array}$ & $54.34 \pm 0.25$ & $0.14 \pm 0.01$ \\
\hline
\end{tabular}

$\mathrm{SD}$ - standard deviation, $\mathrm{PI}$ - polydispersity index.
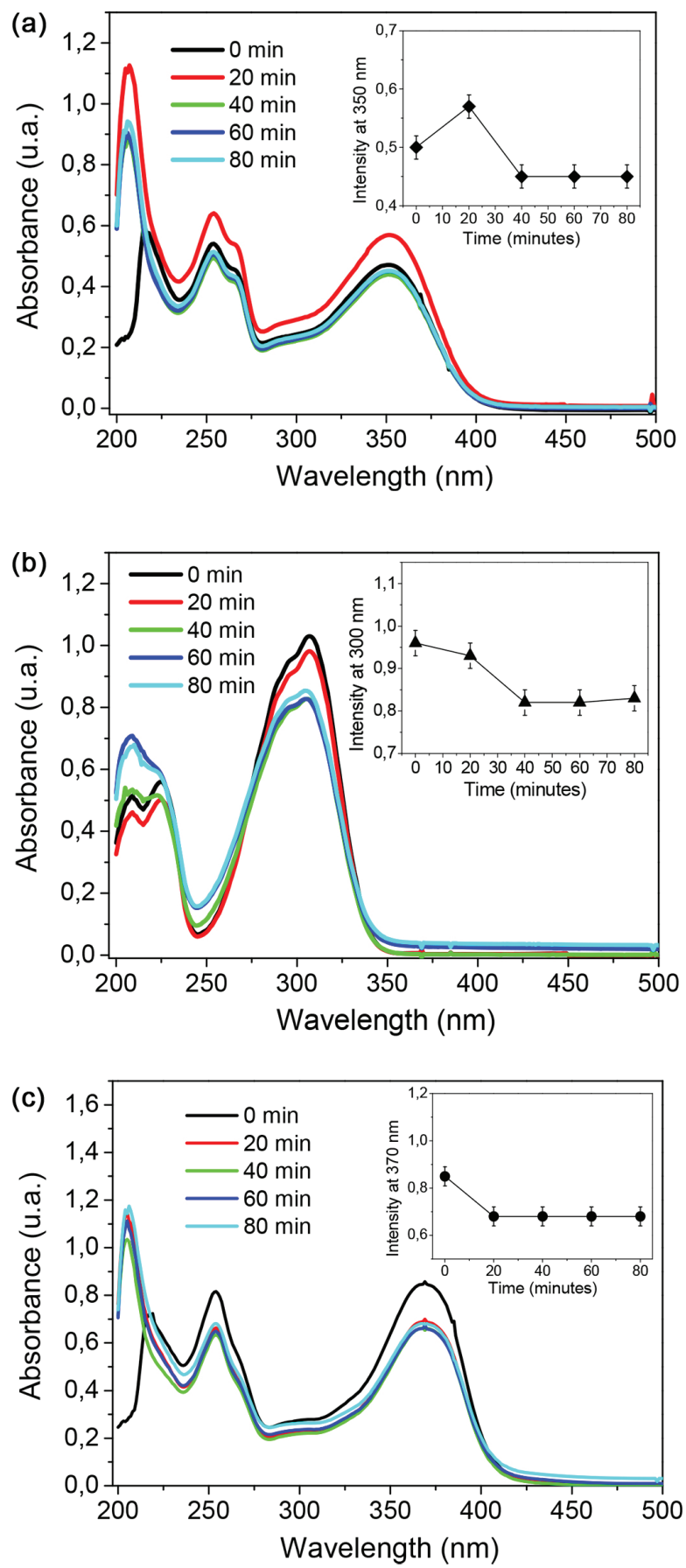

Figure 2. Graphs of photostability of Quercetin 3,7,3',4'-tetraethyl ether (a), standard Ethylhexylmethoxycinnamate (b) and Quercetin (c), in methanol and room temperature. The photostability of the compounds before and after exposure to UVB radiation are shown in the insert 
Table 5. Cell viability of Quercetin and the Quercetin 3,7,3',4'-tetraethyl ether against MTT

\begin{tabular}{|c|c|c|c|c|c|}
\hline \multicolumn{3}{|c|}{ Quercetin } & \multicolumn{3}{|c|}{ Quercetin 3,7,3',4'-tetraethyl ether } \\
\hline $\begin{array}{l}\text { Concentration } \\
\left.(\mu \mathrm{mol} \mathrm{L})^{-1}\right)\end{array}$ & $\begin{array}{c}\text { Concentration } \\
(\mathrm{mg} / \mathrm{mL})\end{array}$ & $\begin{array}{c}\text { Cell Viability } \\
(\%)\end{array}$ & $\begin{array}{c}\text { Concentration } \\
\left(\mu \mathrm{mol} \mathrm{L} \mathrm{L}^{-1}\right)\end{array}$ & $\begin{array}{c}\text { Concentration } \\
(\mathrm{mg} / \mathrm{mL})\end{array}$ & $\begin{array}{c}\text { Cell Viability } \\
(\%)\end{array}$ \\
\hline 10 & $3.02 .10^{-3}$ & 90.46 & 10 & $4.14 .10^{-3}$ & 110.75 \\
\hline 50 & $1.50 .10^{-3}$ & 88.26 & 50 & $2.07 .10^{-3}$ & 112.70 \\
\hline 100 & $3.02 .10^{-4}$ & 89.45 & 100 & $4.14 .10^{-4}$ & 76.13 \\
\hline 200 & $6.04 .10^{-5}$ & 86.69 & 200 & $8.28 .10^{-5}$ & 109.76 \\
\hline 400 & 0.12 & 90.52 & 400 & 0.16 & 105.90 \\
\hline 500 & 0.15 & 93.36 & 500 & 0.21 & 99.61 \\
\hline 600 & 0.18 & 86.01 & 600 & 0.25 & 89.84 \\
\hline 800 & 0.24 & 87.65 & 800 & 0.33 & 91.90 \\
\hline Control & & 100 & Control & & 100 \\
\hline DMSO & & 89.16 & DMSO & & 107.96 \\
\hline
\end{tabular}

allows them to deposit evenly on the surface of the skin, creating a continuous film and consequently increasing the effectiveness of the nanoemulsion in protection against UVA and UVB rays. This type of formulation also protects photosensitive compounds, which is of great interest in cases where the asset degrades during exposure to visible or UV light. ${ }^{34-37}$ Formulations were also evaluated for the addiction of different concentration of Quercetin, (5, 1, 0.2 and $0.1 \%$ ). A precipitate formation could be observed for the three highest concentrations tested, showing the instability of these formulations and the difficulty of solubilizing quercetin even in an oily vehicle. Thus, as previously mentioned, a nanoemulsion with $0.1 \%$ Quercetin was prepared, in which there was no precipitate formation after $24 \mathrm{~h}$ from the preparation time. This concentration was also used for the Quercetin 3,7,3',4'-tetraethyl ether. As it is more hydrophobic than Quercetin, it could be better solubilized within the oily phase, showing no sign of instability or precipitation. It was noticed the reduction of particle size of nanoemulsions with both additives without compromising system stability.

\section{Cell viability}

According to ISO2009 - 10993-5, a substance is considered cytotoxic when the cell viability is less than or equal to $70 \%$. Therefore, the results obtained in the MTT test were compared according to the ISO. The MTT assay provided the data related to Quercetin and Quercetin 3,7,3',4'-tetraethyl ether according to Table 5. Based on the results obtained, it is observed that Quercetin and the derivative are non-toxic in the concentration range of 1 to $800 \mu \mathrm{mol} \mathrm{L}{ }^{-1}$, since the cell viability was higher than $86.69 \%$ for Quercetin and 89.84\% for Quercetin 3,7,3',4'-tetraethyl ether.

\section{CONCLUSIONS}

The photoprotection study performed according to the Mansur methodology showed promising applications for Quercetin 3, 7, 3', 4'-tetraethyl ether which presented an SPF value similar to quercetin. The observed cytotoxicity values prove that, like Quercetin, the derivative is non-toxic at the maximum concentration assessed (800 $\mu \mathrm{mol} \mathrm{L} \mathrm{L}^{-1}$ ). In addition, the photostability test suggests that the derivative is stable after an initial from a small drop in its absorption observed in the first 20 minutes of exposure to UV light. The nanoemulsions containing the $0.1 \%$ Quercetin 3,7,3',4'-tetraethyl ether, 0.1\% Quercetin, 5\% Ethyl-hexyl Methoxycinnamate and Quercetin with $0.1 \%$ Quercetin 3, 7, 3', 4'-tetraethyl ether were stable for $24 \mathrm{~h}$ after preparation and homogeneous in the size of the particles. Nanoemulsions were successfully obtained with particles sizes with the range of 53 to 75 $\mathrm{nm}$. In addition to this, the EPI method consumes low energy in the process of forming emulsions, being economical and meeting industrial demand. Finally, Quercetin 3,7,3',4'-tetraethyl ether is a promising molecule to be incorporated into formulations of sunscreens, due to the greater liphophilicity when compared to Quercetin.

\section{SUPPLEMENTARY MATERIAL}

NMR and IR spectra used in the characterization of the compounds are available from http://quimicanova.sbq.org.br, free of charge.

\section{ACKNOWLEDGMENT}

UFOP, PROPP, CNPQ, FAPEMIG.

\section{REFERENCES}

1. de Souza, F. P.; Rev. Cienc. Farm. Basica Apl. 2013, 34, 69.

2. Dutra, E. A.; Da Costa, D. A. G.; Kedor-Hackmann, E. R. M.; Santoro, M. I. R. M.; Rev. Bras. Cienc. Farm. 2004, 40, 381.

3. Milesi, S. S.; Guterress, S. S.; Caderno de Farmácia 2002, 18, 103.

4. Polonini, C. P.; Lopes, R. S; Beatriz, A., Gomes, R. S.; Silva, A. O.; Lima, R. V. De; Nunes, G. A.; Brandão, M. A. F.; Raposo, N. R. B.; de Lima, D. P.; Quim. Nova 2014, 37, 1004.

5. Ergindemir, H. N.; Aker, A.; Hamitbeyli, A.; Ocal, N.; Molecules 2016, 21,2 .

6. Leite Filho, C. A.; Reis, S. A. G. B.; Rolim, L. A.; Araújo C. R. M.; Gonsalves, A. A.; Rev. Virtual Quim. 2016, 8, 2057.

7. Dos Santos, J. A.; Polonini, H. C.; Suzuki, É.Y.; Da Silva, A. D.; Steroids 2015, 98, 114.

8. Reis, J. S.; Correa, M. A.; Chin, C. M.; Dos Santos, J. L.; Bioorg. Med. Chem. 2014, 22, 2733.

9. Gonçalves, M. C.; Rossoni Jr., J. V.; Rabelo, A. C. S.; Costa, D. C.; Cazati, T.; Taylor, J. G.; dos Santos, V. M. R.; Rev. Virtual Quim. 2018, 10, 600 .

10. Do Nascimento, M. S. T. Dissertação de Mestrado, Universidade Federal do Mato Grosso do Sul, Campo Grande, 2014.

11. Cabral, L. D. Da S.; Pereira, S. De O.; Partata, A. K.; Revista Científica do Itpac 2013, 5, 107.

12. Damiani, E.; Rosati, L.; Castagna, R.; Carloni, P.; Greci, L.; J. Photochem. Photobiol. B 2006, 26, 204. 
13. Morrison, I. D.; Ross, S.; Colloidal Dispersions: Suspensions, Emulsions, and Foams, Wiley: New York, 2002.

14. Oliveira, A. G.; Scarpa, M. V.; Correa, M. A.; Cera, L. F. R.; Formariz, T. P.; Quim. Nova 2004, 7, 1196.

15. Flor, J.; Davolos, M. R.; Correa, M. A.; Quim. Nova 2007, 30, 153.

16. Tadros, T.; Izquierdo, P.; Esquena, J.; Solans, C.; Adv. Colloid Interface Sci. 2004, 109, 303.

17. Choquenet, B.; Couteau, C.; Paparis, E.; Coiffard, L. J. M.; J. Nat. Prod. 2008, 71, 1117.

18. Santos, S.; Matteo, M.; Photochem. Photobiol. 2010, 86, 273.

19. Vicent, F. T.; Simir, T. R.; Del Ciampo, J. O.; Wolga N. O.; Pitol, D. L.; Iyomasa, M. M.; Bentley, M. V.; Fonseca, M. J.; Eur. J. Pharm. Biopharm. 2008, 69, 948.

20. Picq, M.; Prigent, A. F.; Nemoz, G.; Andre, A. C.; Pacheco, H., J. Med. Chem. 1982, 25, 1192

21. Bouchemal, K.; Briançon S.; Perrier, E.; Fessi, H.; Int. J. Pharm. 2004, 280, 241.

22. Prigent, A.F.; Nemoz, G.; Andre, A.C.; Pacheco, H.; J. Med. Chem. 1982, 25, 1192.

23. Molinspiration Cheminformatics, v2015.01, Bratislava University, Slovak Republic, 1986, available at http://www.molinspiration.com/, assessed at February 2019.

24. Seibert, J. B.; Rodrigues, I. V.; Carneiro, S. P.; Amparo, T. R.; Lanza, J. S.; Frezard, F. F.; Souza, G. H. B.; Santos, O. D. H.; Flavour Fragr. J. 2018, 00,1
25. Morais, J. M.; Tese de doutorado, Universidade de São Paulo, Ribeirão Preto, 2008.

26. Harborne, J. B.; The Flavonoids: advances in research since 1986 , Chapman and Hall: London, 1994

27. Agrawal, P. K.; Carbon-13 NMR of Flavonoids, Elsevier: Amsterdam, 1989.

28. Leite Filho, C. A.; Reis, S. A. G. B.; Rolim, L. A.; Araújo, C. R. M.; Gonsalves, A. A.; Rev. Virtual Quim. 2016, 8, 2057.

29. Pedersen, B.; Kristensen, K.; Eur. J. Nucl. Med. 1981, 6, 521.

30. Janjic, J. M., Shao, P., Zhang, S.; Biomaterials 2014, 35, 4958.

31. Zhang, L.; Kosaraju, S. L.; Eur. Polym. J. 2007, 43, 2956.

32. Sadurní, N.; Solans, C.; Azemar, N.; García-Celma, M. J.; Eur. J. Pharm. Sci. 2005, 26, 438.

33. Klassen, P. L.; George, Z.; Warwick, J.; Georgiadou, S.; Colloids Surf., A 2014, A.455, 1

34. Li, X.; Anton, N.; Ta, T. M. C.; Int. J. Nanomed. 2011, 6, 1313.

35. Rebolleda, S.; Sanz, M. T.; Benito, J. M.; Food Chem. 2015, 167, 16.

36. Gorain, B.; Choudhury, H.; Kundu, A.; Colloids Surf., B 2014, B.115, 286.

37. Bouchama, F.; Aken, G.; Van, A. A. J.; Koper, G. J.; Colloids Surf., A 2003, 231, 11 . 